\title{
FUNGICIDAS DE EFEITOS FISIOLÓGICOS NA CULTURA DO CAFÉ CONILON
}

\author{
Thaisa Thomazini Herzog ${ }^{1}$ \\ Bruno Sérgio Oliveira e Silva² \\ Marcelo Barreto da Silva ${ }^{3}$
}

\begin{abstract}
Resumo: Os fungicidas são produtos destinados ao controle dos fitopatógenos de forma a reduzir suas populações a níveis que não interfiram na qualidade e quantidade da produção agrícola. Contudo, diversos trabalhos têm evidenciado os possíveis efeitos de diferentes fungicidas sobre a fisiologia das plantas. Em virtude da possibilidade de alguns fungicidas influenciarem a fisiologia e a produtividade do café conilon além da ação fúngica, objetiva-se distinguir os efeitos das aplicações das estrobilurinas, anilidas, carboxamidas e triazóis na cultura. A metodologia do trabalho consistiu em fazer uma revisão bibliográfica, abordando inicialmente sobre a importância do café conilon. Em seguida, analisou-se as interferências da aplicação de fungicidas na fisiologia e na produção em diversas culturas, inclusive a do café conilon. Verificou-se que alguns fungicidas influenciam na fisiologia e na produtividade das culturas. Entretanto, pouco se sabe sobre o assunto no café conilon.
\end{abstract}

Palavras-chave: Fungicidas; Fisiologia; Coffea canephora.

\footnotetext{
1 Programa de Pós-Graduação em Agricultura Tropical/ Universidade Federal do Espírito Santo, Brasil. E-mail: thaisaherzog@agronoma.eng.br.

2 Consultor Técnico em Café Conilon - Projeto CONILON EFICIENTE/COOABRIEL, Brasil. E-mail: bruno@agronomo.eng.br.

3 Programa de Pós-Graduação em Agricultura Tropical/ Universidade Federal do Espírito Santo, Brasil. E-mail: marcelobarretodasilva@gmail.com.
} 